\title{
Test de cristalización o helecho como herramienta diagnóstica
}

\author{
Fern test as a diagnostic tool
}

\author{
Lizzie Becerra-Gutiérrez 1,3,a; César Tuesta-Arriola $2, b$
}

El test de cristalización o helecho es un método muy utilizado de rutina en los servicios de ginecología para el diagnóstico de ruptura prematura de membrana (RPM) (1). Sin embargo, también se ha demostrado que es útil para evaluar las alteraciones del moco en pacientes con rinitis (2).

Según el protocolo de SEGO del 2004, el $80 \%$ de los casos de RPM se presentaron en gestaciones a término, y el $20 \%$ son de gestaciones pretérmino, resaltando su importancia como causa de morbimortalidad perinatal, por lo que su correcto diagnóstico es crucial para adoptar un tratamiento adecuado, el cual está basado generalmente en la anamnesis y la exploración física. Sin embargo pueden utilizarse pruebas complementarias., dentro de las que destaca el test de cristalización o helecho (3).

El procedimiento por lo general consiste en colocar el líquido existente en el fondo de saco vaginal o de las paredes sobre un portaobjeto, se deja secar por 10 minutos y se observa al microscopio con objetivo de 10X, la formación de helechos ${ }^{(3,4)}$.

Se sabe que la sensibilidad y especificidad para el test de helecho varía en un $51 \%$ a $70 \%$ respectivamente en pacientes $\sin$ trabajo de parto y $98 \%$ y $88 \%$ respectivamente en pacientes con trabajo de parto. Cabe mencionar que una de las razones de la disminución de sensibilidad y especificidad, se debería a la existencia de falsos positivos por huellas dactilares, contaminación con semen o errores durante la técnica (5.6).

Es importante mencionar que esta prueba también podría incluirse como una alternativa de apoyo diagnóstico en el estudio de la rinitis como biomarcador potencial de la función de las células epiteliales dañadas (2).

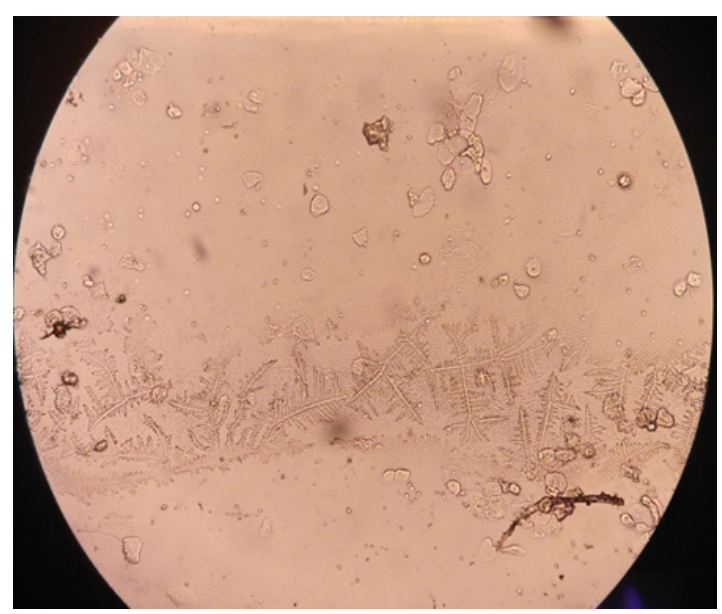

Figura 1. Observación de Cristalización o Helecho. Observación en fresco de líquido vaginal de gestante a pretérmino. Aumento: 400x

1. Facultad de Medicina Humana. Universidad de San Martín de Porres. Chiclayo. Perú

${ }^{2}$ Facultad de Medicina Humana. Universidad Santo Toribio de Mogrobejo

${ }^{3}$ Laboratorio de Inmuno- Virología. Dirección de investigación. Hospital Regional Lambayeque

a Doctor en Microbiología.

${ }^{\mathrm{b}}$ Médico Internista. Hospital Regional Lambayeque 
Conflictos de interés: Los autores declaran no tener conflictos de interés

\section{Fuentes de financiamiento: Autofinanciado}

\section{REFERENCIAS BIBLIOGRÁFICAS}

1. Villalba E Mario R, Ruoti C. Miguel. Utilidad de la proteína de unión al factor de crecimiento similar a la insulina tipo 1 en la ruptura prematura de membrana. An. Fac. Cienc. Méd. (Asunción) [Internet]. 2018 Apr [cited 2021 Feb 16] ; 51( 1 ): 57-64. Available from: http://scielo.iics.una.py/scielo. php?script=sci_arttext\&pid=S1816-89492018000100057\&Ing=en. https:// doi.org/10.18004/anales/2018.051(01)57-064.

2. Gelardi M, Porro G, Quaranta N, Sterlicchio B, Silvestri M, Ciprandi G. The role of the fern test in the treatment of rhinitis. Rev Alerg Mex. 2019 Apr-Jun;66(2):184-191. English. doi: 10.29262/ram.v66i2.544. PMID: 31200417.

3. Diagnóstico de la rotura prematura de membranas. Protocolos SEGO. Prog Obstet Ginecol. 2005;48(11):565-6. DOI: 10.1016/S0304-5013(05)72455-9

4. Monge Acuña T. Ruptura prematura de membranas. Rev.méd.sinerg. [Internet]. 3 de noviembre de 2017 [citado 16 de febrero de 2021];2(11):36. Disponible en: https://revistamedicasinergia.com/index.php/rms/article/ view/98

5. CAUGHEY aron, M., \& ROBINSON Julian, M. (2008). Contemporary Diagnosis and Management of Preterm Premature Rupture of Membranes. Reviws in Obstetrics and Ginecology, 1(1); 11-22.

6. KOCH María, S. P. (Junio 2008). Rotura Prematura de Membranas . Revista de Postgrado de la Cátedra de Medicina, №: 182; Pág: 13-15. 